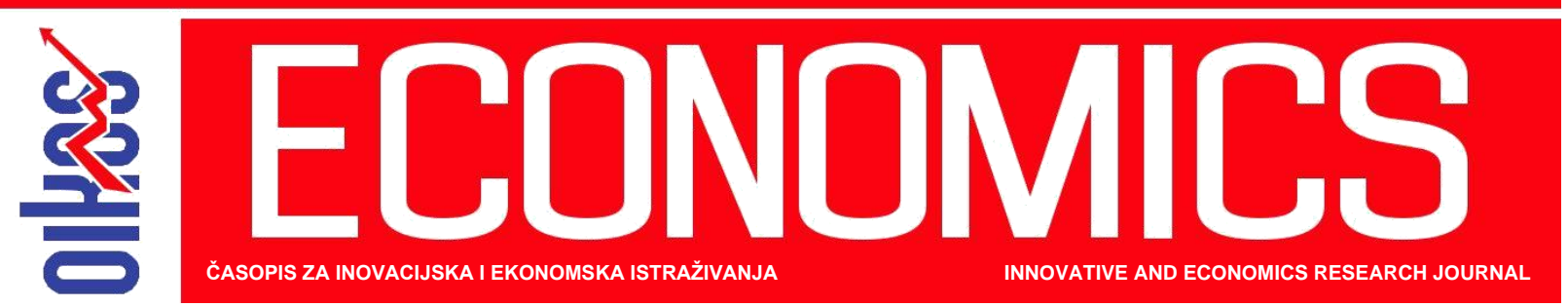

Neznanih junaka 9-11, 76300 Bijeljina, Tel./fax: 055/423-183

Account No.: 555-000-00049162-69; E-mail: novi.economics.institut@ gmail.com; www.economicsrs.com; ISSN: 2303-5005; E-ISSN: 2303-5013

\title{
Retraction note
}

\section{Information about article's retraction}

\section{Editorial}

The article entitled "INCOME SHOCKS AND CHILD MORTALITY RATES: EVIDENCE FROM FLUCTUATIONS IN OIL PRICES”, by Catalina Rivero, Pedro Acuna, published in June, 02. 2021 in the Journal ECONOMICS - Innovative and Economics Research 9(1), pp. 69-84, was retracted and withdrawn from the database of this journal.

Rivero, C. ., \& Acuna, P. . (2021). INCOME SHOCKS AND CHILD MORTALITY RATES: EVIDENCE FROM FLUCTUATIONS IN OIL PRICES .ECONOMICS, 9(1), 6984. https://doi.org/10.2478/eoik-2021-0002

The article has already been published in another journal. 